\title{
Comparison of transperitoneal and retroperitoneal approach for aortoiliac artery occlusive disease
}

\author{
Mohammad Alşalaldeh (D), Bilgin Emrecan (D) \\ Department of Cardiovascular Surgery, Pamukkale University Faculty of Medicine, Denizli, Turkey
}

Received: September 10,2016 Accepted: November 08, 2016 Published online: November 13, 2020

\begin{abstract}
Objectives: This study aims to compare retroperitoneal and transperitoneal approaches in the surgical management of aortoiliac artery occlusive disease and evaluate the advantages and disadvantages of both techniques.

Patients and methods: Between January 2005 and May 2013, a total of 125 patients (116 males, 9 females; mean age 60.9 years; range, 24 to 79 years) with aortoiliac artery occlusive disease were retrospectively analyzed. The patients were classified according to the paramedian incision in the retroperitoneal $(n=84)$ and midline incision in the transperitoneal $(n=41)$ surgical techniques. All patients were examined pre- and postoperatively for the ankle-brachial index (ABI), laboratory blood tests, type of anesthesia, length of hospital and intensive care unit (ICU) stay, amount of blood transfusion oral intake starting time, revision, extra-revascularization need, comorbidities, and mortality.
\end{abstract}

Results: In the retroperitoneal technique, oral intake starting time $(\mathrm{p}<0.001)$, length of $\operatorname{ICU}(\mathrm{p}<0.001)$ and hospital stay $(\mathrm{p}<0.001)$ were shorter, and the amount of blood transfusion $(\mathrm{p}<0.007)$ was lower, compared to the transperitoneal technique. The patients who underwent one-side revascularization in the retroperitoneal group had epidural anesthesia $(n=10)$. There was no significant difference in the mortality, revision, and the need for extra revascularization rates between the groups.

Conclusion: Paramedian incision and retroperitoneal surgical technique in aortoiliac occlusive management is effective and safe and can be done for unilateral extremities under epidural anesthesia.

Keywords: Aortoiliac occlusive disease, median incision, paramedian incision, retroperitoneal technique, transperitoneal technique.

Atherosclerosis is a common disease all over the world and leads to different types of cardiovascular problems, being the most common cause of death. ${ }^{[1]}$ Modern technology of pharmaceutical manufacturing, surgical equipment, and techniques have played a dramatic role in the treatment of such diseases; however, the morbidity and mortality rates are still high, mainly in less developed countries. Currently, different surgical approaches are used to treat this type of vascular disease. Earlier, transperitoneal approach with a midline incision was the most commonly used technique; however, later on, retroperitoneal surgical technique with a paramedian incision, endovascular intervention, and laparoscopic grafting techniques started to take place in the management. ${ }^{[2-4]}$

In recent years, laparoscopic aortobifemoral bypass grafting has been used in the management of aortofemoral artery occlusive disease as a minimally invasive surgical approach, although there is still no study directly comparing laparoscopic aortobifemoral bypass with endovascular treatment for extensive aortoiliac occlusive disease. ${ }^{[5,6]}$ In the present study, we aimed to compare retroperitoneal and transperitoneal approaches in aortoiliac occlusive diseases and to evaluate the advantages and disadvantages of each technique.

\section{PATIENTS AND METHODS}

This retrospective study included a total of 125 patients (116 males, 9 females; mean age 60.9 years; range, 24 to 79 years) with aortoiliac artery occlusive disease between January 2005 and May 2013. Surgical interventions were performed in all patients according to the criteria of the

Corresponding author: Mohammad Alşalaldeh, MD. Pamukkale Üniversitesi Tıp Fakültesi Kalp ve Damar Cerrahisi Anabilim Dalı, 20070 Kınıkl, Denizli, Türkiye. Tel: +90 554 - 3349851 e-mail: dr-alshalaldeh@hotmail.com

\footnotetext{
Citation:

Alşalaldeh M, Emrecan B. Comparison of transperitoneal and retroperitoneal approach for aortoiliac artery occlusive disease. Cardiovasc Surg Int 2020;7(3):170-177.
} 
Trans-Atlantic Inter-Society Consensus II (TASC-II) ${ }^{[7]}$ and only the patients who had ischemic pain, ischemic ulcers, risk of losing extremity, and whose life quality was adversely affected underwent operation (TASC-II C or D)..$^{[7,8]}$ A total of 84 patients were operated by a paramedian incision and retroperitoneal (Group 1), while 41 patients were operated with a midline and transperitoneal approach (Group 2). All patients were examined pre- and postoperatively for the ankle-brachial index (ABI), laboratory blood tests, type of anesthesia, length of hospital and intensive care unit (ICU) stay, amount of blood transfusion oral intake starting time, revision, extra-revascularization need, comorbidities, and mortality.

A written informed consent was obtained from each patient. The study protocol was approved by Pamukkale University, Faculty of Medicine, Ethics Committee (No. 366192). The study was conducted in accordance with the principles of the Declaration of Helsinki.

\section{Surgical technique}

The decision of which surgical technique to be used was made based on the patient's general condition, his/her history of previous abdominal surgeries, and the surgeon's discretion. There were no strict criteria for the decision process.

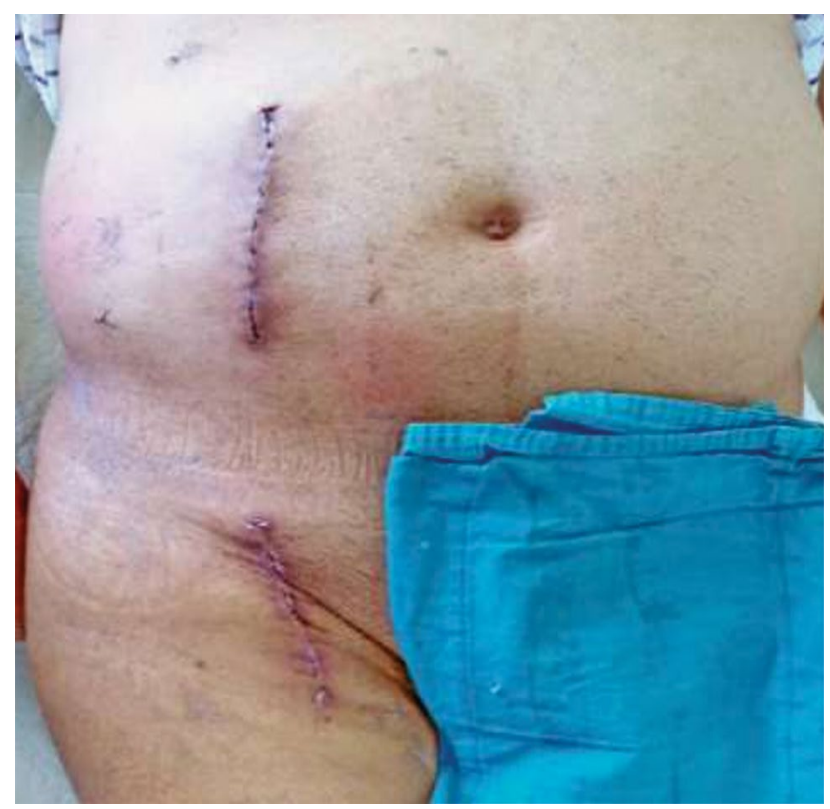

Figure 1. Right sided paramedian retroperitoneal laparotomy and right sided femoral incision for unilateral aortofemoral bypass grafting.
General anesthesia was given to all patients, except for 10 who received epidural anesthesia according to the high risk or upon their request. They were all from the retroperitoneal group and operated for unilateral revascularization.

\section{Retroperitoneal aortoiliac/aortobifemoral bypass with a paramedian incision:}

A paramedian and vertical incision was done, in about $6 \mathrm{~cm}$ far from the midline and about 7 to $8 \mathrm{~cm}$ in length, starting few $\mathrm{cm}$ above the umbilicus downward to the suprapubic level (Figure 1). The anterior rectus sheet and, then, external abdominal muscle were opened at the external side, while the posterior rectus sheet was opened at its semilunar line. All abdominal wall layers were opened, except for the peritoneum (i.e., skin, subcutaneous tissue, superficial fascia, external, then, internal oblique muscle, transversus abdominis muscle, transversalis fascia, and preperitoneal adipose). After retroperitoneal space was reached, dissection was done toward the abdominal aorta and iliac arteries, and the contralateral iliac artery was reached retroperitoneally. In case of aortofemoral bypass, the femoral artery was reached via a tunnel retroperitoneally to the femoral region which was prepared priorly. The anastomosis was done in the same fashion.

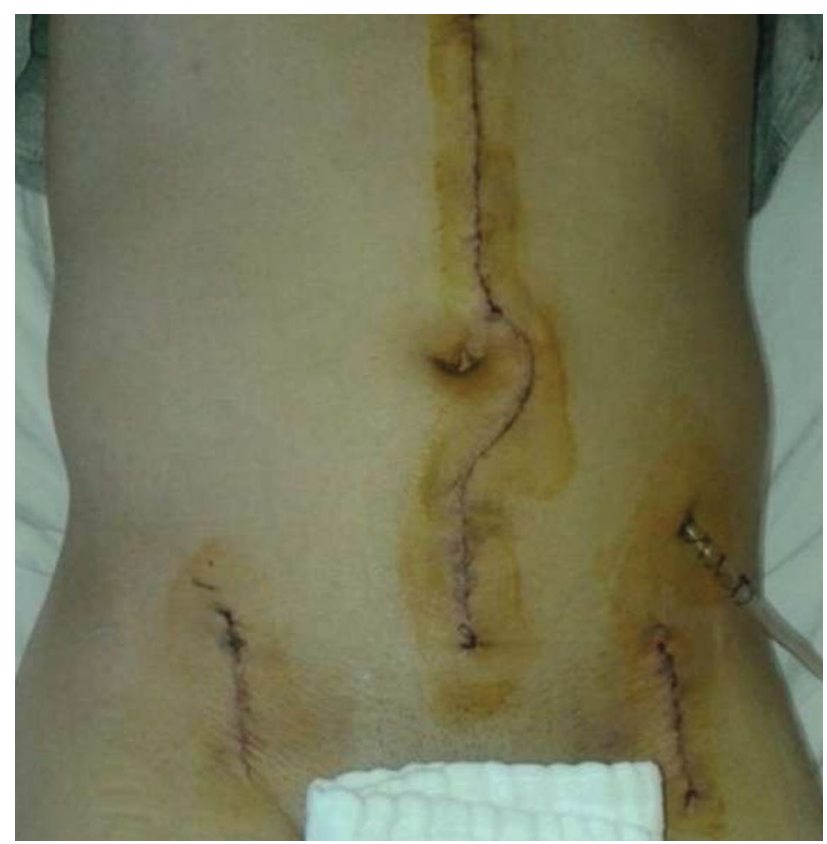

Figure 2. Midline transperitoneal laparotomy and bifemoral incisions for aortobifemoral bypass grafting. 


\section{Transperitoneal aortobiiliac/aortobifemoral bypass with a midline incision:}

Laparotomy was done at the midline starting from the lower border of xiphoid bone toward the lower part of the umbilicus (Figure 2). The abdominal cavity was opened through the peritoneum. The left transverse colon was pulled upward, while the small intestine was pulled to the right side by sterile wet compresses. A gentle dissection and release were done to the abdominal aorta up to renal arteries and downward to the distal iliac arteries. Anticoagulant (heparin) was given at a dose of $1 \mathrm{mg} / \mathrm{kg}$ to maintain the activated clotting time (ACT) at 250 to $350 \mathrm{sec}$. Crossclamping was applied at the proximal abdominal aorta below the renal arteries level. The ' $\mathrm{Y}$ ' shaped Dacron ${ }^{\circledR}$ (JOTEC-Germany) grafts $(16 / 8 \mathrm{~mm})$ were used for aortoiliac or aortobifemoral replacements, while polytetrafluoroethylene grafts were used for femoropopliteal bypass grafting. Longitudinal arteriotomy was done to the aorta and end-to-side anastomosis was achieved by $3 / 0$ or $4 / 0$ poly propylene sutures. Then, cross-clamps were applied to the iliac arteries and released from the abdominal aorta. The legs of the graft were anastomosed to the iliac arteries in an end-to-side fashion by $5 / 0$ polypropylene sutures. In aortobifemoral bypass grafting, the legs of the graft were anastomosed to the common femoral arteries which were exposed through the femoral region incisions priorly.

\begin{tabular}{|c|c|c|c|c|}
\hline Baseline d & $\begin{array}{c}\text { Table } 1 \\
\text { graphic and clinic }\end{array}$ & l data of patients & & \\
\hline & & Surgical technique & & \\
\hline & Group $1(n=84)$ & Group $2(\mathrm{n}=41)$ & Total $(n=125)$ & \\
\hline & $\mathrm{n}$ & $\mathrm{n}$ & $\mathrm{n}$ & $p$ \\
\hline Sex & & & & 0.269 \\
\hline Male & 76 & 40 & 116 & \\
\hline Female & 8 & 1 & 9 & \\
\hline Hypertension & 32 & 16 & 48 & 0.920 \\
\hline Diabetes mellitus & 24 & 10 & 34 & 0.620 \\
\hline Chronic renal failure & 14 & 6 & 20 & 0.771 \\
\hline Cigarette & 55 & 29 & 84 & 0.557 \\
\hline Chronic obstructive pulmonary disease & 28 & 20 & 48 & 0.095 \\
\hline Hyperlipidemia & 34 & 18 & 52 & 0.715 \\
\hline Revision & 11 & 6 & 17 & 0.814 \\
\hline Mortality & 4 & 0 & 4 & 0.302 \\
\hline Anesthesia & & & & 0.030 \\
\hline General anesthesia & 74 & 41 & 115 & \\
\hline Epidural & 10 & 0 & 10 & \\
\hline Revascularization type & & & & $<0.001$ \\
\hline Aortofemoral & 46 & 3 & 49 & \\
\hline Aortobifemoral & 18 & 35 & 53 & \\
\hline Iliofemoral & 18 & 0 & 18 & \\
\hline Aortoiliac & 2 & 3 & 5 & \\
\hline Coronary artery disease & & & & 0.649 \\
\hline Coronary artery bypass grafting & 10 & 6 & 16 & \\
\hline Medical treatment & 28 & 17 & 45 & \\
\hline Stent & 3 & 2 & 5 & \\
\hline Additional operation & & & & 0.081 \\
\hline Femoropopliteal & 19 & 8 & 27 & \\
\hline Bilateral femoropopliteal & 2 & 5 & 7 & \\
\hline
\end{tabular}




\section{Statistical analysis}

Statistical analysis was performed using the PASW version 17.0 software (SPSS Inc., Chicago, IL, USA). Continuous variables were expressed in mean and \pm standard deviation (SD) or median (min-max), while categorical variables were expressed in number and frequency. The chi-square test was used to analyze categorical variables, while the Student t-test was used to analyze continuous variables between the groups. The repeated-measures t-test was performed to compare pre- and postoperative variables. A $p$ value of $<0.05$ was considered statistically significant.

\section{RESULTS}

Only 10 patients in Group 1 were operated under epidural anesthesia, while the other 115 were operated under general anesthesia. Twenty-one patients from

\begin{tabular}{|c|c|c|c|c|}
\hline \multicolumn{5}{|c|}{$\begin{array}{c}\text { Table } 2 \\
\text { Pre- and postoperative data }\end{array}$} \\
\hline & Surgical technique & $\mathrm{n}$ & Mean \pm SD & $p$ \\
\hline \multirow[t]{2}{*}{ Age (year) } & Group 1 & 84 & $61.2 \pm 9.7$ & \multirow{2}{*}{0.597} \\
\hline & Group 2 & 41 & $60.3 \pm 9.5$ & \\
\hline \multirow[t]{2}{*}{ Intensive care unit (day) } & Group 1 & 84 & $0.8 \pm 1.0$ & \multirow{2}{*}{$<0.001$} \\
\hline & Group 2 & 41 & $2.0 \pm 1.3$ & \\
\hline \multirow[t]{2}{*}{ Hospitalization (day) } & Group 1 & 84 & $6.9 \pm 4.1$ & \multirow{2}{*}{$<0.001$} \\
\hline & Group 2 & 41 & $11.2 \pm 5.8$ & \\
\hline \multirow[t]{2}{*}{ Follow-up (month) } & Group 1 & 80 & $24.3 \pm 11.1$ & \multirow{2}{*}{0.841} \\
\hline & Group 2 & 41 & $24.7 \pm 9.6$ & \\
\hline \multirow[t]{2}{*}{ Glucose (mg/dL) } & Group 1 & 84 & $121.8 \pm 48.2$ & \multirow{2}{*}{0.372} \\
\hline & Group 2 & 41 & $130.5 \pm 56.1$ & \\
\hline \multirow[t]{2}{*}{ Preoperative $\mathrm{Hb}$ (gr/dL) } & Group 1 & 84 & $13.3 \pm 1.6$ & \multirow{2}{*}{0.508} \\
\hline & Group 2 & 41 & $13.1 \pm 1.8$ & \\
\hline \multirow[t]{2}{*}{ Postoperative $\mathrm{Hb}$ (gr/dL) } & Group 1 & 84 & $11.1 \pm 1.4$ & \multirow{2}{*}{0.180} \\
\hline & Group 2 & 41 & $13.5 \pm 16.3$ & \\
\hline \multirow[t]{2}{*}{ Preoperative Hct (\%) } & Group 1 & 84 & $39.4 \pm 4.5$ & \multirow{2}{*}{0.649} \\
\hline & Group 2 & 41 & $39.0 \pm 5.4$ & \\
\hline \multirow[t]{2}{*}{ Postoperative Hct (\%) } & Group 1 & 84 & $36.3 \pm 32.4$ & \multirow{2}{*}{0.503} \\
\hline & Group 2 & 41 & $32.9 \pm 2.8$ & \\
\hline \multirow[t]{2}{*}{ Preoperative creatinine $(\mathrm{mg} / \mathrm{dL})$} & Group 1 & 84 & $1.0 \pm 0.5$ & \multirow{2}{*}{0.359} \\
\hline & Group 2 & 41 & $0.9 \pm 0.2$ & \\
\hline \multirow[t]{2}{*}{ Postoperative creatinine (mg/dL) } & Group 1 & 84 & $1.2 \pm 0.9$ & \multirow{2}{*}{0.423} \\
\hline & Group 2 & 41 & $1.0 \pm 0.4$ & \\
\hline \multirow[t]{2}{*}{ Preoperative ankle-brachial index } & Group 1 & 84 & $0.5 \pm 0.1$ & \multirow{2}{*}{0.537} \\
\hline & Group 2 & 41 & $0.5 \pm 0.1$ & \\
\hline \multirow[t]{2}{*}{ Postoperative ankle-brachial index } & Group 1 & 84 & $1.0 \pm 0.1$ & \multirow{2}{*}{0.071} \\
\hline & Group 2 & 41 & $0.9 \pm 0.2$ & \\
\hline \multirow[t]{2}{*}{ Oral intake (day) } & Group 1 & 84 & $1.2 \pm 0.5$ & \multirow{2}{*}{$<0.001$} \\
\hline & Group 2 & 41 & $1.8 \pm 0.8$ & \\
\hline \multirow[t]{2}{*}{ Blood transfusion (unit) } & Group 1 & 84 & $1.3 \pm 1.8$ & \multirow{2}{*}{0.007} \\
\hline & Group 2 & 41 & $2.3 \pm 2.1$ & \\
\hline
\end{tabular}


the retroperitoneal group needed an extra operation for peripheral arterial occlusive diseases such as femoropopliteal bypass grafting, while 11 patients needed to be taken to the operating room once again for exploration due to bleeding or early graft occlusion or distal thromboembolism.

The postoperative mortality was seen only in Group $1(n=4)$. The main type of revascularization was aortofemoral bypass grafting, mainly in Group $1(n=46)$, while a higher number of patients needed aortobifemoral bypass grafting in Group 2 $(\mathrm{n}=35)$. Iliofemoral bypass grafting was done only in Group $1 \quad(n=18)$. Baseline demographic and clinical characteristic of the patients are summarized in Table 1.

The retroperitoneal approach with a paramedian incision showed superiority to the transperitoneal approach with a median incision in terms of the length of ICU stay $(\mathrm{p}<0.001)$ and hospital stay $(\mathrm{p}<0.001)$. The mean length of ICU stay was $0.78 \pm 1$ days in Group 1 and 2.0 \pm 1.3 days in Group 2. The mean

\begin{tabular}{|c|c|c|c|c|}
\hline \multicolumn{5}{|c|}{$\begin{array}{c}\text { Table } 3 \\
\text { Pre- and postoperative data according to surgical incision in patients undergoing bilateral } \\
\text { revascularization }\end{array}$} \\
\hline & Surgical technique & $\mathrm{n}$ & Mean $\pm S D$ & $p$ \\
\hline \multirow[t]{2}{*}{ Age (year) } & Paramedian incision & 18 & $62.3 \pm 8.9$ & \multirow{2}{*}{0.266} \\
\hline & Median incision & 35 & $59.2 \pm 9.6$ & \\
\hline \multirow[t]{2}{*}{ Hospitalization (day) } & Paramedian incision & 18 & $5.39 \pm 1.6$ & \multirow{2}{*}{$<0.001$} \\
\hline & Median incision & 35 & $11.4 \pm 6.1$ & \\
\hline \multirow[t]{2}{*}{ Intensive care unit (day) } & Paramedian incision & 18 & $0.6 \pm 0.9$ & \multirow{2}{*}{$<0.001$} \\
\hline & Median incision & 35 & $2.1 \pm 1.4$ & \\
\hline \multirow[t]{2}{*}{ Blood transfusion (unit) } & Paramedian incision & 18 & $0.7 \pm 0.9$ & \multirow{2}{*}{$<0.001$} \\
\hline & Median incision & 35 & $2.4 \pm 2.2$ & \\
\hline \multirow[t]{2}{*}{ Preoperative $\mathrm{Hb}(\mathrm{gr} / \mathrm{dL})$} & Paramedian incision & 18 & $13.3 \pm 1.9$ & \multirow{2}{*}{0.583} \\
\hline & Median incision & 35 & $13.0 \pm 1.7$ & \\
\hline \multirow[t]{2}{*}{ Postoperative $\mathrm{Hb}$ (gr/dL) } & Paramedian incision & 18 & $11.4 \pm 1.7$ & \multirow{2}{*}{0.557} \\
\hline & Median incision & 35 & $13.9 \pm 17.6$ & \\
\hline \multirow[t]{2}{*}{ Preoperative Hct (\%) } & Paramedian incision & 18 & $39.5 \pm 5.1$ & \multirow{2}{*}{0.555} \\
\hline & Median incision & 35 & $38.6 \pm 5.2$ & \\
\hline \multirow[t]{2}{*}{ Postoperative Hct (\%) } & Paramedian incision & 18 & $33.5 \pm 4.2$ & \multirow{2}{*}{0.467} \\
\hline & Median incision & 35 & $32.7 \pm 2.5$ & \\
\hline \multirow[t]{2}{*}{ Glucose $(\mathrm{mg} / \mathrm{dL})$} & Paramedian incision & 18 & $107.9 \pm 27.7$ & \multirow{2}{*}{0.057} \\
\hline & Median incision & 35 & $130.8 \pm 58.2$ & \\
\hline \multirow[t]{2}{*}{ Preoperative creatinine $(\mathrm{mg} / \mathrm{dL})$} & Paramedian incision & 18 & $1.1 \pm 0.9$ & \multirow{2}{*}{0.151} \\
\hline & Median incision & 35 & $0.9 \pm 0.2$ & \\
\hline \multirow[t]{2}{*}{ Postoperative creatinine $(\mathrm{mg} / \mathrm{dL})$} & Paramedian incision & 18 & $1.2 \pm 0.8$ & \multirow{2}{*}{0.457} \\
\hline & Median incision & 35 & $1.0 \pm 0.4$ & \\
\hline \multirow[t]{2}{*}{ Preoperative ankle-brachial index } & Paramedian incision & 18 & $0.5 \pm 0.1$ & \multirow{2}{*}{0.301} \\
\hline & Median incision & 35 & $0.5 \pm 0.1$ & \\
\hline \multirow[t]{2}{*}{ Postoperative ankle-brachial index } & Paramedian incision & 18 & $1.0 \pm 0.1$ & \multirow{2}{*}{0.140} \\
\hline & Median incision & 35 & $0.9 \pm 0.2$ & \\
\hline \multirow[t]{2}{*}{ Oral intake (day) } & Paramedian incision & 18 & $1.3 \pm 0.6$ & \multirow{2}{*}{0.033} \\
\hline & Median incision & 35 & $1.8 \pm 0.8$ & \\
\hline
\end{tabular}


length of hospital stay was $6.8 \pm 4.0$ days in Group 1 and 11.1 \pm 5.8 days in Group 2. The mean oral intake starting time was earlier in Group 1 than Group 2 $(1.2 \pm 0.5$ days vs. $1.76 \pm 0.7$ days, respectively; $p<0.001)$. The mean amount of blood transfusion was also lower in Group 1 than Group 2 (1.26 U vs. $2.27 \mathrm{U}$, respectively; $\mathrm{p}<0.007$ ) (Table 2 ).

Revascularization type and operations varied among the patients according to the occlusion site. Aortobifemoral bypass grafting were mostly done with a median incision and transperitoneal approach $(n=35)$ and only 18 patients were operated for the same lesion type by the other technique. All iliofemoral bypass grafting procedures $(n=18)$ were done with a paramedian retroperitoneal approach.

When the patients needed extra-revascularization operation for more distal lesions, the extra-grafting bypass operations were done in the same session. There were 19 patients from the retroperitoneal group and eight patients from the transperitoneal group who were operated with unilateral femoropopliteal grafting bypass, while two from the retroperitoneal group and five from the transperitoneal group were operated with bilateral femoropopliteal grafting bypass. Seventeen patients were taken to the operation room postoperatively for revision due to bleeding or early graft occlusion. Eight of them were operated before with a retroperitoneal approach and nine patients were operated with a transperitoneal approach. The reasons for revision was bleeding, mostly from the site of anastomosis.

Mortality was seen only in the retroperitoneal group where four patients (3\%) died postoperatively, three of them were operated with a paramedian aortofemoral and one with aortobifemoral grafting bypass. The causes of mortality were severe pulmonary disease $(\mathrm{n}=2)$, myocardial infarction $(\mathrm{n}=1)$, and resistant metabolic acidosis $(n=1)$. There was no statistically significant difference in the mortality rate between the two groups $(p=0.302)$. In addition, there was no significant difference in the other measurements including laboratory testing $(\mathrm{Hg} \mathrm{p}=0.180$, Hct \% $\mathrm{p}=0.503$, creatinine $\mathrm{p}=0.423)$ and ABI $(\mathrm{p}=0.071)$ (Table 2).

In the subgroup analyses, the incision type and unilateral and bilateral revascularization methods were examined separately. In this study, patients who underwent unilateral revascularization with a paramedian incision were compared with those who underwent unilateral revascularization with a median incision. Accordingly, paramedian incision did not provide a significant superiority to the median incision in unilateral revascularization. On the other hand, after the comparison of the patients who underwent bilateral revascularization with a paramedian incision with those who underwent bilateral revascularization with a median incision, the length of ICU and hospital stay, starting time of oral food intake, and the amount of blood transfusion were found to be statistically significantly superior in favor of the retroperitoneal technique with a paramedian incision (Table 3).

\section{DISCUSSION}

Currently, cardiovascular diseases are the leading cause of death worldwide. Over the past two decades, the mortality from cardiovascular disease has decreased in developed countries, while it still high in less developed ones. ${ }^{[1,9]}$ Recent technology has played a key role in the development of treatment modalities. In the past, aortoiliac occlusive artery disease was primarily treated by transperitoneal laparotomy with a midline incision using vascular grafts, while it can be treated nowadays using novel methods of endovascular intervention techniques or by a paramedian incision and retroperitoneal technique.

In our study, the male-to-female ratio was 12.9:1. The reason for this distinct prevalence difference compared to the literature data can be attributed to our small sample size. In addition, elderly women living in the conservative region where the study was conducted were usually not active and remained asymptomatic, and the number of health institutions in this region is high. Also, the peripheral arterial revascularization operations performed in external centers were not included in this study.

In the present study, two patient groups who underwent revascularization for aortoiliac occlusive diseases were evaluated. We compared the ABI, glucose, hemoglobin, hematocrit, and serum creatinine levels pre- and postoperatively. Comorbidities of the patients, the need for blood transfusion, the length of stay in ICU and hospital, starting time for oral intake, and follow-up periods were examined. Risk factors for morbidity were also assessed. As it is well known, atherosclerosis is one of the risk factors of peripheral arterial disease. Diseases caused by atherosclerosis such as myocardial infarction, stroke, aortic, and lower extremity vascular disease are the 
most important causes of mortality and morbidity in developed countries. Risk factors such as the use of tobacco products, dyslipidemia, hypertension, and diabetes mellitus increase the risk of atherosclerosis, leading to a more complicated course of clinical conditions due to atherosclerosis. ${ }^{[10-12]}$ In our study, we found no significant relationship between any variable and the surgical technique used. The main findings of this study are that the mean oral intake starting time and length of ICU ( $<<0.001)$ and hospital stay were shorter, and the amount of blood transfusion was lower in the retroperitoneal technique, compared to the transperitoneal technique.

In a study comparing retroperitoneal versus transperitoneal approach in revascularization of aortoiliac artery occlusive patients, Sicard et al. ${ }^{[13]}$ reported similar results. The amount of intraoperative blood loss significantly increased $(\mathrm{p}<0.001)$ and the postoperative oral intake starting time was longer $(p<0.001)$ in the transperitoneal technique, while the length of stay in the hospital was shorter $(\mathrm{p}<0.02)$ in retroperitoneal technique. Similar results were also reported in other studies, ${ }^{[14,15]}$ consistent with our findings. In another study which was done by Kalko et al., ${ }^{[16]}$ similar results were reported. In this study, 153 patients were included and 85 of them were operated with a transperitoneal approach, while 68 with a retroperitoneal approach for aortoiliac artery occlusion. The mean oral intake starting time was also shorter in the retroperitoneal approach in this study $(\mathrm{p}<0.001)$.

In cases where aortoiliac occlusion is accompanied by femoropopliteal occlusion, it is a matter of debate whether revascularization should be done for both aortoiliac and femoropopliteal occlusions or it is enough to do it for aortoiliac occlusion alone. It has been supported in many publications that if the blood flow of a deep femoral artery (DFA) is sufficient, peripheral arterial revascularization is not required. ${ }^{[17]}$ The cornerstone for peripheral arterial revascularization decision is the flow of DFA. Recently, hybrid interventions have also started to take place in the treatment of peripheral arterial occlusive diseases. ${ }^{[18]}$ In a study conducted by Madiba et al., ${ }^{[19]}$ 984 lower extremities of 492 patients were evaluated. All patients underwent aortobifemoral graft bypass operation due to aortoiliac artery occlusion disease. A total of 123 extremities of the superficial femoral artery were found to be patent, while it was occluded in 861 extremities. The effect of the patent DFA as runoff was investigated. Five-year patency rate was $80 \%$ in the extremities with the occluded superficial femoral artery and $87 \%$ in the extremities with the patent superficial femoral arteries. The main finding of this study is that, when DFA is patent the development of collateral arteries to the popliteotibial artery is high so, there is no need for distal revascularization. ${ }^{[19]}$

In our study, additional interventions were applied only to the patients with advanced peripheral arterial disease. Intermittent claudication alone was not considered as an indication for distal revascularization. In our clinic, in case of aortoiliac occlusive disease associated with peripheral arterial occlusions, the decision to perform extra-revascularization to the peripheral vessels depends on the flow of the DFA and whether there are signs of acute ischemia or non-healing ischemic wounds distally. Considering the possible relationship between reoperation and surgical technique, no significant difference was found between the techniques used in this study.

Furthermore, there was no significant difference in the follow-up duration between the two techniques. The prolonged follow-up was mainly due to the causes of acute circulatory disorders (i.e., thromboembolism) or to the situations in which complete revascularization was not achieved in the first operation. In our study, mortality was seen only in Group $1(\mathrm{n}=4,3 \%)$, indicating no statistically significant difference. This may be related to the number of patients in each group.

Considering the difficulties of the surgical techniques, the surgical field was limited in Group 1 compared to Group 2. In general, there was a need for one more assistant specialist in Group 1 to help in retracting the nearby organs and tissues to achieve a better surgical field for the primary surgeon. In aortobifemoral or aortobiiliac operations, extending the femoral/iliac graft to the contralateral side was difficult, as well. At the same time, it is safer with less possibility of intestinal injury. ${ }^{[20]}$ In Group 2, there were difficulties in operating abdomens with adhesions due to previous surgeries or inflammatory processes, resulting in incisional hernia, evisceration, peritonitis, and long-lasting ileus. ${ }^{[21]}$

The main limitation to this study is that the number of transperitoneal group patients may have affected the study results. The retrospective nature of the study is also another limitation. Further largescale, long-term, prospective studies are needed to confirm these results. 
In conclusion, retroperitoneal approach with a paramedian incision in treating aortoiliac artery occlusive disease seems to be superior to the transperitoneal approach with a median incision with less blood transfusion, shorter ICU and hospital stay, and earlier start of oral intake.

\section{Declaration of conflicting interests}

The authors declared no conflicts of interest with respect to the authorship and/or publication of this article.

\section{Funding}

The authors received no financial support for the research and/or authorship of this article.

\section{REFERENCES}

1. Roth GA, Johnson C, Abajobir A, Abd-Allah F, Abera SF, Abyu G, et al. Global, Regional, and National Burden of Cardiovascular Diseases for 10 Causes, 1990 to 2015. J Am Coll Cardiol 2017;70:1-25.

2. Emrecan B, Onem G, Ocak E, Arslan M, Yagci B, Baltalarli A, et al. Retroperitoneal approach via paramedian incision for aortoiliac occlusive disease. Tex Heart Inst J 2010;37:70-4.

3. Twine CP, Lane IF, Williams IM. The retroperitoneal approach to the abdominal aorta in the endovascular era. J Vasc Surg 2012;56:834-8.

4. Djedovic M, Rustempasic N, Djedovic S, Totic D, Solakovic $\mathrm{S}$, Mujanovic E, et al. Comparison of transperitoneal and retroperitoneal approach in aorto iliac occlusive disease. Med Arch 2013;67:249-51.

5. Helgetveit I, Krog AH. Totally laparoscopic aortobifemoral bypass surgery in the treatment of aortoiliac occlusive disease or abdominal aortic aneurysms - a systematic review and critical appraisal of literature. Vasc Health Risk Manag 2017;13:187-99.

6. Günertem E, Akay HT. Laparoscopic aortobifemoral bypass: An underappreciated treatment option for aortoiliac occlusive disease. Turk J Vasc Surg 2021. [Ahead of Print]

7. Norgren L, Hiatt WR, Dormandy JA, Nehler MR, Harris $\mathrm{KA}$, Fowkes FG, et al. Inter-Society Consensus for the Management of Peripheral Arterial Disease (TASC II). J Vasc Surg 2007;45 Suppl S:S5-67.

8. Tendera M, Aboyans V, Bartelink ML, Bartelink ML, Baumgartner I, Erbel R, et al. Peripheral arterial diseases (diagnosis and treatment of) Guideline ESC Clinical Practice Guidelines 2011. p. 27-42.
9. Celermajer DS, Chow CK, Marijon E, Anstey NM, Woo KS. Cardiovascular disease in the developing world: prevalences, patterns, and the potential of early disease detection. J Am Coll Cardiol 2012;60:1207-16.

10. Onat A. Risk factors and cardiovascular disease in Turkey. Atherosclerosis 2001;156:1-10.

11. Dalbeni A, Giollo A, Tagetti A, Atanasio S, Orsolini G, Cioffi $G$, et al. Traditional cardiovascular risk factors or inflammation: Which factors accelerate atherosclerosis in arthritis patients? Int J Cardiol 2017;236:488-92.

12. Erdoğan G, Yenerçağ $M$, Arslan U. The relationship between blood viscosity and acute arterial occlusion. Journal Cardiovascular Emergencies 2010;6:7-12.

13. Sicard GA, Freeman MB, VanderWoude JC, Anderson CB. Comparison between the transabdominal and retroperitoneal approach for reconstruction of the infrarenal abdominal aorta. J Vasc Surg 1987;5:19-27.

14. Başel H. Comparison of retroperitoneal and transperitoneal procedures in aortoiliac occlusive diseases. Turk Gogus Kalp Dama 2009;17:249-53.

15. Emrecan B, Alshalaldeh M, Girgin S, Durna F. Paramedian retroperitoneal approach for revascularization of aortoiliac occlusive disease. Turk Gogus Kalp Dama 2015;23:672-7.

16. Kalko Y, Uğurlucan M, Başaran M. Nargileci E, Banach $\mathrm{M}$, Alpagut U, et al. Comparison of transperitoneal and retroperitoneal approaches in abdominal aortic surgery. Acta Chir Belg 2008;108:557-62.

17. Diehm N, Savolainen H, Mahler F, Schmidli J, Do DD, Baumgartner I. Does deep femoral artery revascularization as an isolated procedure play a role in chronic critical limb ischemia?. Journal of Endovascular Therapy J Endovasc Ther 2004;11:119-24.

18. Murakami A. Hybrid Operations in Patients with Peripheral Arterial Disease. Ann Vasc Dis 2018;11:57-65.

19. Madiba TE, Mars M, Robbs JV. Aortobifemoral bypass in the presence of superficial femoral artery occlusion: does the profunda femoris artery provide adequate runoff? J R Coll Surg Edinb 1998;43:310-3.

20. Beşir Y, Gokalp O, Iner H, Peker I, Yetkin U, Donmez, et al. An alternative method of transperitoneal graft introduction in aortobifemoral bypass surgery. Cardiovasc J Afr 2015;26:45-8.

21. Ozcan AV, Emrecan B, Gökşin I. Aortobifemoral bypass via paramedian incision and retroperitoneal approach for aortoiliac occlusive disease. Acta Chir Belg 2013;113:182-6. 